\title{
Immediate outcome of day case laparoscopic cholecystectomy
}

\author{
Chandio A*, Khatoon Z, Chandio K, SM Naqui and SA Naqvi \\ Manchester Royal Infirmary \& Trafford General Hospital, UK
}

\begin{abstract}
Introduction: There has been revolution in Surgery over the past four decade's recent advances in surgical and anaesthetic techniques financial incentives for the hospital have changed the emphasis in patient selection in day surgery, the increase in day surgery rates for appropriate procedures has the potential to improve the service for patients by achieving shorter waiting times, allowing patient choice and making best use of NHS. The Royal College of Surgeons of England, in 1992, concluded that day surgery is better than inpatient care for many conditions and that it can be an effective way of reducing waiting times
\end{abstract}

Objective: Aim of this study was to find out safety and the immediate outcome of laparoscopic cholecystectomy as a day case in District General Hospital

Methods: Retrospective identification of 101, patients underwent a laparoscopic cholecystectomy as a day case following parameters: age, gender, comorbidities obesity, presentation with acute cholecystitis, pancreatitis or obstructive jaundice

Results: Eleven patients (10.89) patients were unplanned admission and transferred to a Regional Hospitals. Three patients (2.97\%) required conversion to open cholecystectomy. One patient (0.99\%) required drain insertion, and five patients (4.95\%) pain control. Two patients (1.98\%) bleeding one from the Gall Bladder fossa which was controlled, another patient developed an epigastric port bleeding and gone Re-laparoscopy and resolved the issue with removal of clot and control of bleeding. Ninety $(89.10 \%)$ patients were discharged home after laparoscopic cholecystectomy.

Conclusion: Day case Laparoscopic cholecystectomy can be performed safely in District General Hospital, shorter waiting time, allowing patient choice, economic benefit, and making best use of NHS

\section{Background}

The modern era of day surgery began in the years following World War II with the realization that prolonged bed rest was associated with high rates of postoperative complications such as deep vein thrombosis [1]. The move towards early ambulation led to earlier discharge and, for the first time, the economic benefits of day surgery were noted [2]. In 1990 Audit commission review NHS value for money report identified several interventions, including laparoscopic cholecystectomy that clinical opinion suggested could be carried out as day cases. Following the review, the Department of Health set up a task force on day surgery along with $£ 15$ million ( $€ 21$ million; $\$ 23$ million) of capital funds to expand the number of dedicated day surgery units. By 2001, almost all trusts had at least one unit. Audit Commission follow up review in 2001 pushed for further progress: 'If all trusts could achieve the levels of the best performers (the upper quartile of the distribution of the percentage of day cases), 120,000 existing inpatients in England and Wales could be treated as day cases to the benefit of all concerned. The Royal College of Surgeons of England, in 1992, concluded that day surgery is better than inpatient care for many conditions and that it can be an effective way of reducing waiting times [3].

Aim of this study was to find out the safety and immediate outcome of laparoscopic cholecystectomy after a Day case surgical procedures.

\section{Methods}

All the patients undergoing Laparoscopic cholecystectomy presented in the surgical Day unit at Trafford General Hospital from November 2015 to October 2016 under a single surgeon's service were retrospectively identified from the hospital's operative records. Data were retrieved by detailed review of the hospital case notes, including radiographic imaging and operative course. The following preoperative parameters were recorded: age, sex, obesity, presentation with acute cholecystitis, pancreatitis or obstructive jaundice, ultrasonography detection of gallbladder wall thickening or gallbladder stones, and the presence of common bile duct (CBD) stones. The majority of operations were performed by consultant surgeons with a minimum of 10 years' experience in performing laparoscopic cholecystectomy, via a standard 4-port method, achieving pneumo peritoneum using the Hasson technique for carbon dioxide insufflation.

We collected the data for unplanned admission/transferred to an acute hospital, and for any immediate complications (Tables 1-3).

All these patients were ASA I or II.

\section{Inclusion and exclusion criteria}

The inclusion criteria symptomatic gall stones, ASA grades 1and 2 who had adult company at home for the first 48 hours Patients with complicated gall stones were thoroughly assessed for suitability for a day case procedure and were offered day case LC only if the surgical procedure was not expected to be difficult.

Correspondence to: Chandio A, Manchester Royal Infirmary \& Trafford General Hospital, UK, E-mail: chandioashfaq@yahoo.com

Received: March 02, 2017; Accepted: March 24, 2017; Published: March 27, 2017 
Table 1. Patients outcome after day case laparoscopic Cholecystectomy.

\begin{tabular}{|c|c|c|}
\hline Numbers & $\begin{array}{c}\text { Transferred to acute hospital } \\
\text { (Immediate not Discharged home) }\end{array}$ & $\begin{array}{c}\text { Immediate Discharged to } \\
\text { home }\end{array}$ \\
\hline 101 & $11(10.89 \%)$ & \\
\hline Female 78 & $\begin{array}{c}\text { Open cholecystectomy 3 (2.97\%) } \\
\text { Post-op pain 5 }(4.95 \%)\end{array}$ & Discharged home without \\
Male 23 & Drain 1 $(0.99 \%)$ & any issue 90 $(89.10 \%)$ \\
Age /years 25-76 & Bleeding 2 (1.98\%) & \\
& a, Epigastric port & \\
& b, GB fossa & \\
\hline
\end{tabular}

Table 2. Un planned admission.

\begin{tabular}{|c|c|c|}
\hline Reason & Number & Percentage \\
\hline Conversion to open & 3 & 2.97 \\
\hline Pain & 5 & 4.95 \\
\hline Bleeding & 2 & 1.98 \\
\hline Drain & 1 & 0.99 \\
\hline
\end{tabular}

Table 3. Operative /Histology Findings.

\begin{tabular}{|c|c|c|}
\hline Findings & Number & Percentage \\
\hline Cholecystitis & 35 & 34.65 \\
\hline Adhesions & 38 & 37.62 \\
\hline Simple cholecystectomy & 22 & 21.78 \\
\hline Abnormal anatomy & 03 & 2.97 \\
\hline Mucocele & 02 & 1.98 \\
\hline Bile leak & 01 & 0.99 \\
\hline
\end{tabular}

Exclusion criteria severe sleep apnoea, Obese, previous extensive abdominal surgery, ASA grade 3 or more.

\section{Discharge criteria}

Patients were discharged if they were able to tolerate oral diet, mobilise safely, haemodynamically stable without significant pain, nausea and or vomiting.

Primary outcome was classified as a successful day case Laparoscopic Cholecystectomy and discharge inpatients identified for a day case procedure preoperatively.

Secondary outcomes were considered as failed day case discharges (due to surgical complications, post-operative pain, nausea and vomiting and other reasons for failed discharge) and readmissions following a successful day case procedure and discharge.

\section{Statistical analysis}

All data was recorded using a Microsoft Excel Spread sheet. Data were analysed using the Statistical Package for Social Sciences (SPSS, version 17). Mean values were compared using the Student $t$ test

\section{Result}

During this period, 101 patients underwent Laparoscopic cholecystectomy. The female to male ratio was 3:1 (78 versus 23). The mean patient age for undergoing laparoscopic cholecystectomy was 51 years (range, 25 to 76 ) and $77.2 \%$ were female. Of this cohort, 3 patients $(2.97 \%)$ underwent conversion to open cholecystectomy.

Eleven (10.89\%) patients out of 101, after day case laparoscopic cholecystectomy were unplanned admission and transferred to Manchester Royal Infirmary for further management. Five (4.95\%) patients had no surgical issues but pain management, three $(2.97 \%)$ patients converted to open due to difficult anatomy and multiple adhesions. One $(0.99 \%)$ patient had a drain inserted. One $(0.99 \%)$ patient had epigastric port bleeding and underwent re-laparoscopy and was for 24 hour observations. One (0.99\%) patient got bleed from GB fossa. Overall 90/101 (89.10\%) patients were discharged home after Outpatient laparoscopic cholecystectomy.

\section{Intraoperative indications for conversion}

The most common reason for conversion was a diseased gallbladder. This included inability to define anatomy in 3 patients, a contracted or fibrotic gallbladder with foreshortening of the cystic duct, and dense adhesions of the gallbladder to either the duodenum or the CBD.

\section{Discussion}

Laparoscopic cholecystectomy is considered the treatment of choice for gallbladder disease. It confers definite advantages over the open procedure. The increase in day surgery rates for appropriate procedures has the potential to improve the service for patients by achieving shorter waiting times, allowing patient choice and making best use of NHS. The move towards early ambulation led to earlier discharge and, for the first time, the economic benefits of day surgery were noted [4]. The Audit commission's analysis suggested that if all health authorities in England and Wales, 'performed day surgery consistently at readily achievable levels for each of 20 common procedures, an additional 186,000 patients could be treated each year without increased expenditure. As day case patients cost less to treat than patients who stay overnight as inpatients (in 2013-14, the average day case cost was $£ 698$ and the average elective inpatient case $£ 3,375$ ), the increasing proportion of day case activity has helped reduce overall costs

Day surgery rates for specific procedures still vary between individual surgeons, between hospitals and even between regions. Day case laparoscopic cholecystectomy in all SHAs ranged from $23 \%$ to $56 \%$ ! [5]. The reasons for such variations are complex and remain largely unexplained, but often reflect an inability to organise healthcare effectively and follow guidelines [6-9]. Whilst these variations were understandable in the development phase of day surgery, they become increasingly difficult to justify as we move to a genuine National Healthcare system, with equal access to treatment for all. A new generation of surgeons and anaesthetists who are more familiar with the skills and techniques necessary to provide high-quality day surgery should ensure that most of these extreme variations disappear over the next few years. The rate for day case laparoscopic cholecystectomy in the UK is just under $40 \%$ and still shows large variations between surgeons, trusts and regions [5]. The reasons for this relate to fears about reactionary haemorrhage, delayed haemorrhage and bile leak. The NHS Institute published a clinical pathway in 2007 which noted that $70 \%$ of laparoscopic cholecystectomies could be safely performed as day cases [10] and this target has been recommended to NHS commissioners as part of the 18-week programme [11]. Successful day case laparoscopic cholecystectomy relies on rigorous patient selection, accepting only well-motivated and non-obese patients, and attention to detailed surgical technique. It is now accepted that the majority of patients are appropriate for day case laparoscopic cholecystectomy unless there is a valid reason why an overnight stay would be to their benefit. If inpatient surgery is being considered it is important to question whether any strategies could be employed to enable the patient to be treated as a day case. Although the National Institute of Health and Clinical Excellence (NICE) guidance on pre-operative investigations [12] is widely used, one recent study showed no difference in the outcomes of day surgery patients even when all pre-operative investigations were omitted [13]. Fitness for a procedure should relate to the patient's health as determined at pre-operative assessment and not limited by arbitrary limits such as ASA status, age or BMI [14-16]. 
Patients presenting with acute conditions requiring urgent surgery can be efficiently treated as day cases via a semi-elective pathway [17]. Effective pre-operative assessment and preparation with protocoldriven, nurse-led discharge are fundamental to safe and effective day and short stay surgery. Several recent publications provide useful advice on the establishment and running of both services [18-21]. From the end of the 1970s onwards, several retrospective series were published $[22,23]$, as well as two small-randomized studies in which day surgery was compared with inpatient treatment [24-26]. A randomized study compared how much patient's valued different treatments [27]. These studies showed that day surgery is just as safe and effective, and, in addition, cheaper. In two of the three studies, patients were at least as content with day surgery $[26,27]$. Abdominal pain is still the main cause of in-hospital morbidity, unplanned admission and readmission; as is seen in our study adequate pain relief is essential in day case surgery. Various methods, such as peritoneal instillation of local anesthetic agents $[28,29]$ and wound infiltration with local anesthetic agents [30], have been attempted to decrease postoperative pain. While much of the postoperative pain in laparoscopic cholecystectomy is deep in nature, laparoscopy port sites should always be infiltrated with a long-acting local anaesthetic [31]. The morbidity of LC has been reported to be $4 \%$ $20 \%$ [32]. This compares well with our study.

In our study 11 patients were unplanned admission and transferred to Regional Hospital for admission /observation due to non-availability / lack of inpatients surgical facility, beds, as three patients Laparoscopic - Open cholecystectomy due to complex anatomy, five patients for pain management, three patients one each drain, bleeding from epigastric artery and bleeding from gallbladder fossa. Our conversion rate was three percentage $2.97 \%$, compares well with literature [33,34], this may be due to small number of cases we operated during study period. There were no morbidity, our morbidity rate was zero. Readmission / unplanned admission $8.91 \%$ compares favorably with those reported by other centers $[35,36]$.

Our overall unplanned admission rate of $8.91 \%$ compares favorably with other national and international centers [37-42] and our readmission rate within $48 \mathrm{hrs}$ was zero. Our overall day case Laparoscopic cholecystectomy rate for single surgeon was $1.94 \%$ for the period of this study our overall day case discharge rate was $89.10 \%$ this compares favourably with other international and national centers. This study includes a post discharge follow up of only patient's with unplanned admission. Where there is ongoing contact between the Day Surgery Unit and the patient or between patient and GP, re-admission rates are lower [43-45]. This study show that day case Laparoscopic Cholecystectomy is feasible and safe in a district general hospital, reduce waiting times, economic benefits though there is further room for improvement within our service.

\section{Conclusion}

Day case Laparoscopic cholecystectomy is safe in a district hospital, shorter waiting time, allowing patient choice, economic benefit, and making best use of NHS. Each Surgeon should do the self-evaluation in a view to improve the quality of our health care system.

\section{Conflict of interest statement}

None of the authors have any conflict of interest to declare.

\section{References}

1. Asher RA (1947) The dangers of going to bed. Br Med J 2: 967. [Crossref]

2. Palumbo LT, Paul RE, Emery FB (1952) Results of primary inguinal hernioplasty. AMA Arch Surg 64: 384-394. [Crossref]
3. Guidelines for Day Case Surgery, Royal College of Surgeons of England, revised edition March 1992

4. Palumbo LT, Paul RE, Emery FB (1952) Results of primary inguinal hernioplasty. AMA Arch Surg 64: 384-394. [Crossref]

5. Department of Health (2004) 10 high impact changes for service improvement and delivery. NHS Modernisation Agency.

6. NHS Institute for Innovation and Improvement. Focus on: Cholecystectomy. 2007.

7. Association of Anaesthetists of Great Britain and Ireland. Preoperative assessment and patient preparation - the role of the anaesthetist 2. London: AAGBI; 2010.

8. Orchard M, Ellms J, McWhinnie D (2010) What do we mean by 'theatre utilisation'? J One Day Surg 1. 20: 4-6.

9. NHS Institute for Innovation and Improvement. Focus on: Cholecystectomy. 2007.

10. Department of Health (2006) Tackling hospital waiting: the 18 week patient pathway. London: Department of Health.

11. Farquharson EL (1955) Early ambulation; with special reference to herniorrhaphy as an outpatient procedure. Lancet 269: 517-519. [Crossref]

12. National Institute for Health and Clinical Excellence. NICE Clinical Guideline 3 Pre-operative tests. The Use of Routine Preoperative Tests for Elective Surgery, 2003. http://www.nice.org.uk/CG003 (accessed 03 / 01 / 2011).

13. Chung F, Yuan H, Yin L, Vairavanathan S, Wong DT (2009) Elimination of preoperative testing in ambulatory surgery. Anesth Analg 108: 467-475. [Crossref]

14. Ansell GL, Montgomery JE (2004) Outcome of ASA III patients undergoing day case surgery. Br J Anaesth 92: 71-74. [Crossref]

15. Aldwinckle RJ, Montgomery JE (2004) Unplanned admission rates and post discharge complications in patients over the age of 70 following day case surgery. Anaesthesia 59: 57-59. [Crossref]

16. Canet J, Raeder J, Rasmussen LS, Enlund M, Kuipers HM, et al. (2003) Cognitive dysfunction after minor surgery in the elderly. Acta Anaesthesiol Scand 47: 1204-1210. [Crossref]

17. Smith I (2009) Emergency day surgery. J One Day Surg 19: 2-3.

18. Association of Anaesthetists of Great Britain and Ireland (2010) Pre-operative Assessment and Patient Preparation - The Role of the Anaesthetist 2. London: AAGBI.

19. British Association of Day Surgery. Ten Dilemmas in Preoperative Assessment for Day Surgery. London: BADS, 2009.

20. British Association of Day Surgery. Organisational Issues in Pre-Operative Assessmen for Day Surgery. London: BADS, 2010.

21. NHS Institute for Innovation and Improvement. Website: www.productivity.nhs.uk Dashboard/For/ National/And/25th/Percentile [accessed 01.08.12].

22. Michelsen M, Walter F (1982) [Comparison of outpatient and inpatient operations for inguinal hernia (1971 to 1978) (author's transl)]. Zentralbl Chir 107: 94-102. [Crossref]

23. Pineault R, Contandriopoulos AP, Valois M, Bastian ML, Lance JM (1985) Randomized clinical trial of one-day surgery. Patient satisfaction, clinical outcomes, and costs. Med Care 23: 171-182. [Crossref]

24. Prescott RJ, Cutherbertson C, Fenwick N, Garraway WM, Ruckley CV (1978) Economic aspects of day care after operations for hernia or varicose veins. J Epidemiol Community Health 32: 222-225. [Crossref]

25. Ruckley CV, Cuthbertson C, Fenwick N, Prescott RJ, Garraway WM (1978) Day care after operations for hernia or varicose veins: a controlled trial. Br J Surg 65: 456-459. [Crossref]

26. Ramyil VM, Ognonna BC, Iya D (1999) Patient acceptance of outpatient treatment for inguinal hernia in Jos, Nigeria. Cent Afr J Med 45: 244-246. [Crossref]

27. Mitchell JB, Harrow B (1994) Costs and outcomes of inpatient versus outpatient hernia repair. Health Policy 28: 143-152. [Crossref]

28. Lepner U, Goroshina J, Samarütel J (2003) Postoperative pain relief after laparoscopic cholecystectomy: a randomised prospective double-blind clinical trial. Scand J Surg 92: 121-124. [Crossref]

29. Mjåland O, Raeder J, Aasboe V, Trondsen E, Buanes T (1997) Outpatient laparoscopic cholecystectomy. Br J Surg 84: 958-961. [Crossref]

30. Keulemans Y, Eshuis J, de Haes H, de Wit LT, Gouma DJ (1998) Laparoscopic cholecystectomy: day-care versus clinical observation. Ann Surg 228: 734-740. [Crossref] 
31. Ballal M, David G, Willmott S, Corless DJ, Deakin M, Slavin JP (2009) "Conversion after laparoscopic cholecystectomy in England," Surgical Endoscopy and Other Interventional Technique 23: 2338-2344. [Crossref]

32. David GG, Al-Sarira SAA, Deakin WM, Corless DJ, Slavin JP (2008) "Management of acute gallbladder disease in England," British Journal of Surgery 95: 472-476. [Crossref]

33. Briggs CD, Irving GB, Mann CD, Cresswell A, Englert L, et al. (2009) Introduction of a day-case laparoscopic cholecystectomy service in the UK: a critical analysis of factors influencing same-day discharge and contact with primary care providers. Ann R Coll Surg Engl 91: 583-590. [Crossref]

34. Singleton RJ, Rudkin GE, Osborne GA, Watkins DS, Williams JA (1996) Laparoscopic cholecystectomy as a day surgery procedure. Anaesth Intensive Care 24: 231-236. [Crossref]

35. Ali A, Chawla T, Jamal A (2009) [Not Available]. J Minim Access Surg 5: 8-13. [Crossref]

36. Jain PK, Hayden JD, Sedman PC, Royston CM, O’Boyle CJ (2005) A prospective study of ambulatory laparoscopic cholecystectomy: training, economics and patient benefits. Surg Endosc 19: 1082-1085. [Crossref]

37. Sherigar JM, Irwin GW, Rathore MA, Khan A, Pillow K, et al. (2006) Ambulatory laparoscopic cholecystectomy outcomes. JSLS 10: 473-478. [Crossref]
38. Briggs CD, Irving GB, Mann CD, Cresswell A, Englert L, et al. (2009) Introduction of a day-case laparoscopic cholecystectomy service in the UK: a critical analysis of factors influencing same-day discharge and contact with primary care providers. Ann $R$ Coll Surg Engl 91: 583-590. [Crossref]

39. Victorzon M, Tolonen P, Vuorialho T (2007) Day-case laparoscopic cholecystectomy: treatment of choice for selected patients? Surg Endosc 21: 70-73. [Crossref]

40. Lau H, Brooks DC (2002) Contemporary outcomes of ambulatory laparoscopic cholecystectomy in a major teaching hospital. World J Surg 26: 1117-1121. [Crossref]

41. Psaila J, Agrawal S, Fountain U, Whitfield T, Murgatroyd B, et al. (2008) Day-surgery laparoscopic cholecystectomy: factors influencing same-day discharge. World J Surg 32: 76-81. [Crossref]

42. Kiely JM, Brannigan AE, Foley E, Cheema S, O'Brien W, et al. (2001) Day case laparoscopic cholecystectomy is feasible. Ir J Med Sci 170: 98-99. [Crossref]

43. Sherigar JM, Irwin GW, Rathore MA, Khan A, Pillow K, et al. (2006) Ambulatory laparoscopic cholecystectomy outcomes. JSLS 10: 473-478. [Crossref]

44. Briggs CD, Irving GB, Mann CD, Cresswell A, Englert L, et al. (2009) Introduction of a day-case laparoscopic cholecystectomy service in the UK: a critical analysis of factors influencing same-day discharge and contact with primary care providers. Ann R Coll Surg Engl 91: 583-90. [Crossref]

45. Leeder PC, Matthews T, Krzeminska K, Dehn TC (2004) Routine day-case laparoscopic cholecystectomy. Br J Surg 91: 312-316. [Crossref]

Copyright: $(02017$ Chandio A. This is an open-access article distributed under the terms of the Creative Commons Attribution License, which permits unrestricted use, distribution, and reproduction in any medium, provided the original author and source are credited. 